\title{
Telemedicine Using Stationary Hard-Wire Audiovisual Equipment or Robotic Systems in Critical Care: A Brief Review
}

\author{
Nidhi S. Nikhanj, $M D^{1,2}$ \\ Robert A. Raschke, MD1,2 \\ Robert Groves, MD1,2 \\ Rodrigo Cavallazzi, $M D^{3}$ \\ Ken S. Ramos, $\mathbf{M D}^{1}$
${ }^{1}$ Arizona College of Medicine-Phoenix
Phoenix, AZ USA
Phoenix, AZ USA
Louisville, KY USA \\ ${ }^{2}$ Banner University Medical Center-Phoenix \\ ${ }^{3}$ University of Louisville School of Medicine
}

A shortage of critical care physicians in the United States has been widely recognized and reported (1). Most intensive care units (ICUs) do no not have a formally-trained intensivist in their staff despite compelling evidence that high-intensity intensivist staffing leads to better patient outcomes $(1,2)$. Critical care telemedicine is one potential solution that has expanded rapidly since its inception in 2000 (3). In its simplest form, telemedicine leverages audiovisual technology and the electronic medical record to provide remote two-way communication between a physician and a patient. Current telemedicine models differ by the type of hardware facilitating remote audiovisual interaction, the location of the provider, and the type of patient-care service provided. We collectively have experience with several of these models and feel that future telemedicine programs will likely integrate the most advantageous aspects of each with an increasing role for telemedicine robotics.

The dominant current model for providing critical care telemedicine in large healthcare systems utilizes stationary hard-wired audiovisual equipment linking each ICU room to a centralized control location (4). Typically, this control center provides surveillance of a large number of patients using computerized decision support software linked to the EMR - a single physician can cover approximately 100 patients with the appropriate support infrastructure. This model also provides the ability to remotely "round" on ICU patients and to quickly respond to questions posed by nursing or medical emergencies across a broad geographic range. This approach requires a high up-front capital cost approximated at 50-100K per hospital bed covered (5).

Data supporting the benefit of this model of ICU telemedicine has been mixed, but several considerations are important in appraising the literature. A double-blinded RCT for ICU telemedicine intervention is not feasible. Heterogeneity in clinical workflows and staffing models across the country should be considered when assessing the internal validity and generalizability of published studies. For instance, Thomas and colleagues concluded that a telemedicine ICU service resulted in no overall improvement in mortality or length of stay (LOS) (6), but the tele-intensivists in the study were limited by only being allowed to intervene in the care of less than a third of the study patients. Nassar and colleagues published a negative study in a healthcare system in which 
resident and attending physicians were already available in-house for overnight patient care (7). Likely, the potential benefit of a telemedicine program can be optimized in a clinical setting in which other physicians are not physically available at the locality 24/7 and telemedicine intensivists are allowed to appropriately intervene when indicated.

Despite these difficulties, there is a growing body of evidence that suggests a centralized telemedicine ICU model is effective in a number of areas including: improvements in compliance with evidence based practices $(8,9)$, increased job satisfaction of ICU nurses (10) and reduction in the cost of care of the sickest patients in the institutional setting (11). Other studies suggest that a telemedicine platform can reduce mortality and LOS by allowing for earlier intensivist involvement, promoting adherence to best practices, shortening alarm response times and improving access to ICU performance data that can be used to drive continuous quality improvement $(12,13)$.

Commercially available telemedicine robots are mobile units equipped with a digital camera, microphone and monitor screen that provides two-way audiovisual communications with the control center via a wireless internet connection (14).

Telemedicine robots can be operated with much lower initial capital costs - for instance, an ICU group at a large acute care hospital might provide coverage at a rural healthcare setting using a single robot (15). Such a system can be used for daily rounding or for reactive consultation. Like hard-wired systems, telemedicine robots have been shown to be well accepted by providers (16) and patients (17), and their use has been associated with reduced ICU length-of-stay and decreased delay in response to clinical events by the physician (18).

Telemedicine robotic systems have several disadvantages - they do not provide largescale EMR surveillance leveraging computerized decision support logic and they are significantly less efficient than hard-wired systems for high-volume patient care since they have to physically relocate from patient room to patient room. However, unique capabilities of telemedicine robots are being developed that cannot be duplicated by hard-wired systems. Telemedicine robots can be equipped with a digital stethoscope (19). They can perform physical examination elements that require tactile communication - such as the determination of the Glasgow coma scale (20). A robotic arm can be used to remotely perform point-of-care ultrasonography. This has been successfully operationalized for cardiac, abdomino-pelvic, and vascular indications $(21,22)$. Telemedicine robots have been developed that can place peripheral or central venous catheters (23). The development of surgical robots that incorporate tomographic capability and that can perform battlefield stabilization procedures in either autonomous or teleoperative modes (24) provide a glimpse of the potential for telemedicine robots in the ICU.

Although healthcare systems currently implementing telemedicine services will likely choose either a hard-wired or a robotic model - largely based on cost and the volume of required services - we believe the optimal telemedicine system of the future will and should incorporate both technologies. Real-time data acquisition coupled with ready access to timely interventions constitute the basis for faster deployment of precision health care strategies in the ICU setting. 


\section{References}

1. Kelley MA, Angus D, Chalfin DB, Crandall ED, et al. The critical care crisis in the United States: A report from the profession. Chest. 2004;125:1514-7. [CrossRef] [PubMed]

2. Pronovost PJ, Angus DC, Dorman T, Robinson KA, et al. Physician staffing patterns and clinical outcomes in critically ill patients. JAMA. 2002;288:2151-62. [CrossRef] [PubMed]

3. Rosenfeld BA, Dorman T, Breslow MJ, et al. Intensive care unit telemedicine: alternate paradigm for providing continuous intensivist care. Crit Care Med. 2000;28:3925-31. [CrossRef] [PubMed]

4. Kahn JM, Cicero BD, Wallace DJ, Iwashyna TJ. Adoption of intensive care unit telemedicine in the United States. Crit Care Med. 2014;42:362-8. [CrossRef] [PubMed]

5. Kumar G, Falk DM, Bonello RS, et al. The costs of critical care telemedicine programs: A systematic review and analysis. Chest. 2013;143:19-29. [CrossRef] [PubMed]

6. Thomas EJ, Lucke JF, Wueste L. Association of telemedicine for remote monitoring of intensive care patients weith mortality, complications and length of stay. JAMA. 2009;302:2671-78. [CrossRef] [PubMed]

7. Nassar BS, Vaughan MS, Jiang L, Reisinger HS, et al. Impact of an intensive care unit telemedicine program on patient outcomes in an integrated health care system. JAMA Intern Med. 2014;174:1160-7. [CrossRef] [PubMed]

8. Ventataraman R, Ramakrishnan N. Outcomes related to telemedicine in the intensive care Unit. Crit Care Clinics 2015;31:225-37. [CrossRef] [PubMed]

9. Youn BA. ICU process improvement using telemedicine to enhance compliance and documentation for the ventilator bundle. Chest. 2006;130:(meeting abstracts) 226Sc.

10. Hoonakker PL, Carayon P, McGuire K, et al. Motivation and job satisfaction of teleICU nurses. J Crit Care. 2013;28:890-901. [CrossRef] [PubMed]

11. Franzini L, Sail KR, Thomas EJ, et al. Costs and cost-effectiveness of a telemedicine intensive care unit program in six intensive care units in a large health care system. J Crit Care. 2011;26:329e1-6. [CrossRef] [PubMed]

12. Lilly CM, Cody S, Zhao H. Hospital mortality, length of stay and preventable complications among critically ill patients before and after tele-ICU reengineering of critical care processes. JAMA. 2011;305:2175-83. [CrossRef] [PubMed]

13. Lilly CM, Zubrow MT, Kempner KM, Reynolds H, et al. Critical Care telemedicine: Evolution and state of the art. Crit Care Med. 2014;42:2429-36. [CrossRef] [PubMed]

14. Chung KK, Grathwohl KW, Poropatich RK, Wolf SE, et al. Robotic telepresence: Past present and future. Journal of Cardiothoracic and Vascular Anesthesia. 2007;21:593-6. [CrossRef] [PubMed]

15. Murray C, Ortiz E, Kubin C. Application of a robot for critical care rounding in small rural hospitals. Crit Care Nurs Clin North Am. 2014;26:477-85. [CrossRef] [PubMed]

16. Reynolds EM, Grujovski A, Wright T, Foster M, Reynolds HN. Utilization of robotic remote presence technology within North American intensive care units.

Telemedicine and e-health. 2012;18:507-15. [CrossRef] [PubMed] 
17. Sucher JF, Todd SR, Jones SL, Throckmorton T, et al. Robotic telepresence: A helpful adjunct that is viewed favorably by critically ill surgical patients. Am J Surg. 2011;202:843-7. [CrossRef] [PubMed]

18. Vespa PM, Miller C, Hu X, Nenov V, et al. Intensive care unit robotic telepresence facilitates rapid physician response to unstable patients and decreased cost in neurointensive care. Surgical Neurology. 2007;67:331-7. [CrossRef] [PubMed]

19. Lakhe A, Sodhi I, Warrier J, Sinha V. Development of digital stethoscope for telemedicine. J Med Eng Technol. 2016;40:20-4. [CrossRef] [PubMed]

20. Adcock AK, Kosiorek H, Parich P, Chauncey A, Wu Q, Demaerschalk BM. Reliability of robotic telemedicine for assessing critically ill patients with the full outline of unresponsiveness score and Glasgow coma scale. Telemed J E Health. 2017 Jan 13. [CrossRef] [PubMed]

21. Avgousti S, Panayides AS, Jossif AP, Christoforou EG, et al. Cardiac ultrasonography over $4 G$ wireless networks using a tele-operated robot. Healthc Technol Lett. 2016;3:212-7. [CrossRef] [PubMed]

22. Georgescu M, Sacccomandi A, Baudron B, Arbeille PL. Remote sonography in routine clinical practice between two isolated medical centers and the university hospital using a robotic arm: A 1-year study. Telemed J E Health. 2016;22:276-81. [CrossRef] [PubMed]

23. Kobayashi Y, Hong J, Hamano R, Okada K, Fujie MG, Hashizume M. Development of a needle insertion manipulator for central venous catheterization. Int $\mathrm{J}$ Med Robot. 2012;8(1):34-44. [CrossRef] [PubMed]

24. Garcia P, Rosen J, Kapoor C, Noakes M, et al. Trauma Pod: a semi-automated telerobotic surgical system. Int J Med Robot. 2009;5:136-46. [CrossRef] [PubMed] 